\title{
Structural and Kinetic Analyses of Herpes Simplex Virus Type 1 Latency- associated Transcripts in Human Trigeminal Ganglia and in Cell Culture
}

Philip R. Krause, Kenneth D. Croen, Jeffrey M. Ostrove, and Stephen E. Straus

Medical Virology Section, Laboratory of Clinical Investigation, National Institute of Allergy and Infectious Diseases, National Institutes of Health, Bethesda, Maryland 20892

\begin{abstract}
Only one herpes simplex virus type 1 (HSV-1) gene is expressed in sensory neurons of latently infected animals and humans, yielding two RNAs, called latency-associated transcripts (LATs). The LATs appear to modulate virus reactivation. In mice and rabbits the $5^{\prime}$ origins, kinetics of synthesis, and splicing pattern of the LATs are well established. Because these details of LAT structure and expression have not been defined in humans, we sought to do so. Using primer extension and Northern hybridization analyses, we demonstrate that in human trigeminal ganglia, the smaller (1.35 kb) HSV-1 transcript differs from the larger (1.85 kb) LAT by excision of an intron near its $5^{\prime}$ end; they are otherwise colinear, and $5^{\prime}$ coterminal. In infected cells only the $1.85 \mathrm{~kb}$ LAT is detected. Its expression is inhibited by cycloheximide or acyclovir, indicating this LAT is synthesized late in the viral replicative cycle. All of these features of the LATs in humans are consistent with those reported in rabbits and mice and further validate the animal models of human HSV-1 infection. (J. Clin. Invest. 1990. 86:235-241.) Key words: herpes infection • viral latency • neurons
\end{abstract}

\section{Introduction}

A fundamental hallmark of herpes simplex virus (HSV) ${ }^{1}$ infection of humans is its ability to recur (1). Abundant evidence indicates that recurrent infections arise as a result of reactivation of latent virus in sensory nerve ganglia. The virus gains access to the ganglia early in infection by local spread from epithelial cells to sensory nerve endings and ascent up the axon. The latent state is characterized by persistence of the viral genome in an episomal form in neuronal nuclei (2). Only one of the $\mathbf{8 0}$ or more viral genes is active until as yet undefined signals trigger reactivation via expression of the remaining genes and the resultant replication and assembly of progeny virions. Virus then spreads centrifugally to cause a recurrent mucocutaneous infection.

Transcription of the single gene that is active in latency has primarily been examined in rabbits and mice, in which studies

Address reprint requests to Dr. Stephen E. Straus, Bldg. 10, Room 11N113, 9000 Rockville Pike, Bethesda, MD 20892.

Received for publication 4 December 1989 and in revised form 27 February 1990.

1. Abbreviations used in this paper: HSV, herpes simplex virus; HSV-1, HSV type 1; LAT, latency-associated transcripts.

The Journal of Clinical Investigation, Inc.

Volume 86, July 1990, 235-241 of HSV type 1 (HSV-1) infected sensory ganglia revealed the expression of two abundant viral RNAs, termed latency-associated transcripts (LATs) (3-9). The smaller LAT, or possibly a pair of transcripts estimated to be $1.3-1.5 \mathrm{~kb}$ in size, are spliced forms of a larger 2.0-2.3-kb transcript. The LATs appear to be localized to the ganglion neuronal nuclei. They possess common $5^{\prime}$ start sites within the long inverted repeat sequences of the genome and there are thus two copies of the LAT gene per virus. They overlap the gene encoding the viral immediate-early protein ICPO (see reference 10 for a discussion of ICP0), but are transcribed from the opposite DNA strand relative to the ICPO message. Studies of ganglia from mice latently infected with HSV-1 indicate that the LATs are not required for the establishment or maintenance of latency. Rather, they appear to play a role in promoting viral reactivation (11-13).

Studies of human tissues also demonstrated abundant HSV-1 LATs in latently infected trigeminal nerve ganglion cell nuclei. The LATs were estimated to be $1.85-2.0 \mathrm{~kb}$ and $1.35-1.5 \mathrm{~kb}$ in length (14-19). No other viral transcription has been detected in human tissues.

In the present work we undertook a detailed examination of the nature, structure, and expression of HSV-1 LATs in human tissues. Should these aspects of HSV-1 latency in human tissues resemble the findings in rabbits and mice, they would further validate the use of the animal models in the study of HSV disease pathogenesis.

\section{Methods}

Cells and infections. Vero cells were grown at $37^{\circ} \mathrm{C}$ in $5 \% \mathrm{CO}_{2}$ incubators in a 1:1 mixture of minimal essential medium (MEM)/199 (Quality Biological, Inc., Rockville, MD), supplemented with 10\% FBS (Quality Biological, Inc.), glutamine $(29.2 \mathrm{mg} / \mathrm{ml})$, aureamycin $(2.6$ $\mathrm{mg} / \mathrm{ml})$, streptomycin $(25 \mathrm{mg} / \mathrm{ml})$, and penicillin $(100 \mathrm{U} / \mathrm{ml})$. For some experiments, cells were treated with acyclovir $(30 \mu \mathrm{M}$; Burroughs-Wellcome Co., Research Triangle Park, NC), beginning $24 \mathrm{~h}$ before infection, while in others, cycloheximide $(50 \mu \mathrm{g} / \mathrm{ml}$, Boehringer-Mannheim Biochemicals, Indianapolis, IN) was added $3 \mathrm{~h}$ before infection.

Cells were infected with a plaque titered stock of HSV-1 strain KOS, or with a low passage HSV-1 clinical isolate recovered from a recurrent lip lesion of an immune competent patient. Human trigeminal ganglia removed at autopsy performed within $24 \mathrm{~h}$ of death were frozen and stored at $-70^{\circ} \mathrm{C}$ until the RNA was extracted as described (15).

RNA purification. RNA was purified from infected or uninfected Vero cells by lysis in situ and from human trigeminal ganglia by polytron homogenization in $\mathbf{4 M}$ guanidinium thiocyanate (Fluka, Buchs, Switzerland) with $0.5 \%$ sarkosyl. RNA was purified by the guanidinium thiocyanate/cesium chloride method as described (20). Yields were estimated by spectrophotometry, and averaged $150 \mu \mathrm{g} / 75 \mathrm{~cm}^{2}$ tissue culture flask and $100 \mu \mathrm{g}$ per trigeminal ganglion.

DNA homologous to the long repeats of HSV-1 strain KOS was cloned into plasmid pGEM 3Z (Promega Biotec, Madison, WI), which contains SP6 and T7 polymerase initiation sites to allow single- 
stranded RNA transcription from inserts in the plasmid templates. RNA markers for hybridization controls were prepared by in vitro transcription, from the appropriate clones using SP6 or T7 polymerases (21), transcribed in the same direction as the LATs. These reactions yielded full length RNAs homologous to the HSV-1 1,660-bp Eco RV-Hinc II fragment (bases 1,479-3,139 relative to the junction of the unique long segment $\left[U_{L}\right]$ and the internal repeat [ $\left[R_{L}\right]$, see Fig. 1 for a map), the 2,866-bp Sph I-Sph I fragment (bases 2,913-5,779), and the 786-bp Sph I-Sph I fragment (bases 2,127-2,913).

Northern hybridizations. RNA samples $(\sim 5 \mu \mathrm{g}$ per lane) were subjected to electrophoresis in $20 \mathrm{mM}$ morpholinopropanesulfonic acid (MOPS; Sigma Chemical Co., St. Louis, MO) buffer (pH 7.0) through $1.5 \%$ agarose- $6 \%$ formaldehyde gels, as previously described (22). RNA was transferred to nitrocellulose paper or Nytran membranes (Schleicher \& Schuell, Inc., Keene, NH), hybridized, and washed according to the instructions of the manufacturer. Membranes were autoradiographed with Kodak XAR-5 film in cassettes with intensifying screens.

Hybridization probes. Oligonucleotide probes designed to detect RNA transcription in the region of the LATs (see Table I) were chosen based on the known DNA sequence of HSV-1 strain 17, kindly provided by $\mathrm{D}$. McGeoch $(10,23)$. The probes $(20$-mers) were manufactured on a DNA synthesizer (model 380A; Applied Biosystems, Inc., Foster City, CA), purified free of partial length oligonucleotides by use of oligonucleotide purification columns purchased from Applied Biosystems, Inc., and 5 ' end-labeled in the presence of ${ }^{32} \mathrm{P}-\gamma$-ATP (Amersham Corp., Arlington Heights, IL) using T4 polynucleotide kinase (Life Technologies/Bethesda Research Laboratories, Gaithersburg, MD) or $3^{\prime}$ end-labeled in the presence of ${ }^{32} \mathrm{P}-\alpha$-dATP with terminal deoxynucleotidyl transferase (Boehringer-Mannheim). Unincorporated counts were removed by ethanol precipitation. Approximately $6-10 \times 10^{6} \mathrm{cpm}$ were used per Northern hybridization. Gel-purified double-stranded DNA probes from the HSV-1 KOS Sal I-Hinc II subfragment region (see Fig. 1) were prepared as previously described (15) and radiolabeled in vitro to a specific activity of $\sim 10^{8}-10^{9}$ $\mathrm{cpm} / \mu \mathrm{g}$ by nick translation in the presence of ${ }^{32} \mathrm{P}-\alpha-\mathrm{dCTP}$ (Amersham Corp.).

Primer extension. Primer extension was done by a slight modification of the procedure of Spalholz (24). RNA (10 $\mu \mathrm{g})$ purified from tissue culture cells or human trigeminal ganglia was incubated with 10 mM methyl-mercury hydroxide (Morton Thiokol, Denver, CO) at $42^{\circ} \mathrm{C}$ for $10 \mathrm{~min}$. 2-mercaptoethanol (Sigma Chemical Co.) was added to a final concentration of $200 \mathrm{mM}$ and the RNA was held at room temperature for $5 \mathrm{~min} .5^{\prime}$ end-labeled probes ( $\sim 2$ pmol per reaction) for primer extension were annealed to the RNA in the presence of 100 $\mathrm{mM}$ sodium chloride, $20 \mathrm{mM}$ Tris ( $\mathrm{pH} \mathrm{7.6)}$, and $0.1 \mathrm{mM}$ EDTA by heating at $90^{\circ} \mathrm{C}$ for $3 \mathrm{~min}$, incubating at $56^{\circ} \mathrm{C}$ for $20 \mathrm{~min}$, and then cooling to $42^{\circ} \mathrm{C}$ over $20 \mathrm{~min}$. Primer extension with cloned Moloney Murine Leukemia Virus (M-MLV) reverse transcriptase (Bethesda Research Laboratories) was conducted at $37^{\circ} \mathrm{C}$ for $1 \mathrm{~h}$ according to the instructions of the manufacturer, using $1 \mathrm{mM}$ dNTPs (Bethesda Research Laboratories), $50 \mu \mathrm{g} / \mathrm{ml}$ actinomycin D (Boehringer-Mannheim), and $100 \mu \mathrm{g} / \mathrm{ml}$ nuclease-free BSA (Bethesda Research Laboratories). Primer extended products were then extracted with phenol and chloroform, precipitated, and washed in ethanol, and one-quarter of the product was subjected to electrophoresis through $8 \mathrm{M}$ urea, $6 \%$ polyacrylamide denaturing gels at $60 \mathrm{~W}$ for $4 \mathrm{~h}$, dried, and autoradiographed as described above for Northern blot analyses. Primer extended products were sized relative to a DNA sequence ladder from an unrelated gene.

\section{Results}

Splicing of HSV-1 LATs. In earlier studies of sequences that are transcribed during acute and latent HSV-1 infections, cloned genomic fragments spanning the region of the viral long repeats (Fig. 1) were gel purified and used as probes in
HSV-1

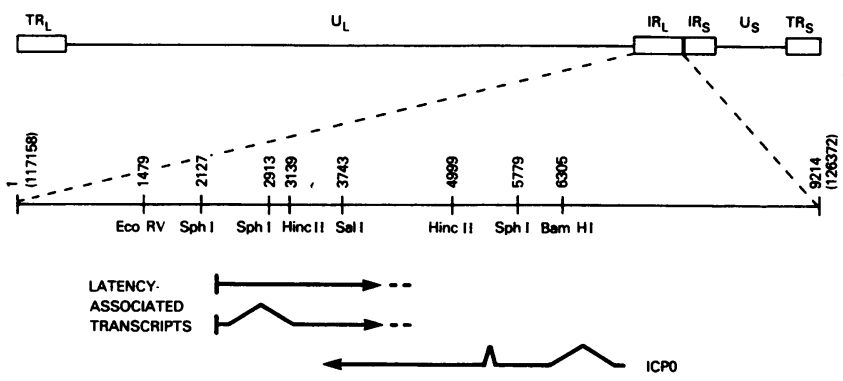

Figure 1. Map of HSV-1 genome and summary of data on physical characterization of the latency-associated transcripts. Bases are labeled relative to the start of the long repeats.

Northern hybridizations. In those experiments we showed that a probe consisting of the 1,256-bp Sal I-Hinc II fragment (bases 3,743-4,999 relative to the junction of the repeat with the unique long $\left[U_{L}\right]$ segment) hybridizes to both the larger and smaller LATs in latently infected human trigeminal ganglia, but only to the larger LAT and the overlapping ICPO transcript in acutely infected Vero cells (15). To more accurately map the LATs and to discern regions of identity between the larger and smaller transcripts, Northern hybridizations were performed using synthetic oligonucleotide probes representing the sequences spanning this area of the genome (Fig. 1).

Each oligonucleotide probe was hybridized to four different RNA preparations. These included a ganglion RNA demonstrated by previous Northern hybridization to contain both the larger and smaller LATs, a ganglion RNA which showed no evidence of LAT transcription upon Northern hybridization, RNA from Vero cells infected for $24 \mathrm{~h}$ with HSV-1 at a multiplicity of two plaque forming units (pfu) per cell, and in vitro transcribed RNA markers representing the 786-bp Sph I fragment (spanning bases 2,127-2,913 relative to the junction of the repeat and unique sequences), the 1,660-bp Eco RVHinc II fragment (spanning bases 1,479-3,139), and the 2,866-bp Sph I fragment (spanning bases 2,914-5,779). These markers were used to verify the quality of the hybridization conditions and, moreover, these controls allowed us to easily discriminate between the $1.85-\mathrm{kb}$ HSV-1 LAT and $18 \mathrm{~S}$ ribosomal RNA, which migrate to similar positions in the formaldehyde-agarose gels.

Typical Northern hybridizations using the oligonucleotide probes are shown in Fig. 2. The oligonucleotide probe spanning bases 2,282-2,301 detected only the 786- and 1,660-b control marker RNAs. The oligonucleotide probe representing bases 2,400-2,419 detected these same marker RNAs, both the $1.85-\mathrm{kb}$ and the 1.35-kb LAT RNAs from a known positive ganglion, but only the 1.85-kb LAT in RNA from HSV-1-infected Vero cells. Neither LAT was detected in the negative ganglion. The probe spanning bases $2,711-2,730$ detected only the 1.85-kb LAT in RNA from HSV-1-infected Vero cells and from the positive ganglion, as well as the appropriate marker RNAs. The 2,866-b marker could now be detected due to the location of this oligonucleotide's sequence. Failure of the probe to detect the smaller transcript in several similar hybridizations indicates that the 1.35-kb LAT lacks significant homology to this sequence. The probe spanning bases 4,089 


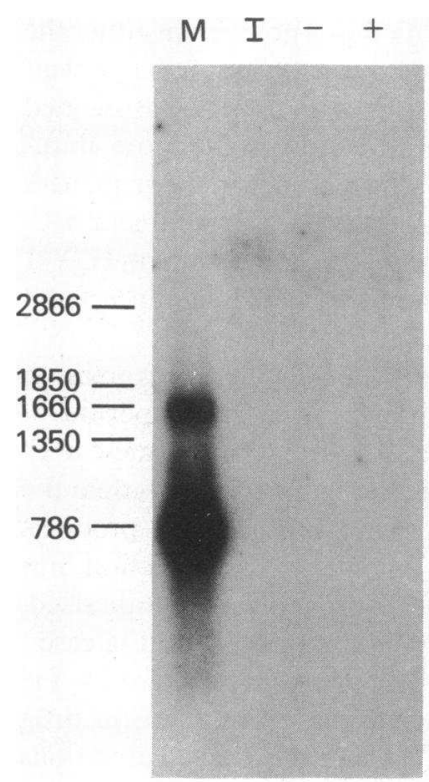

2282-2301

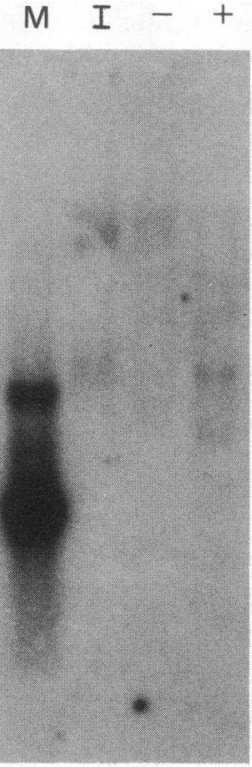

$2400-2419$

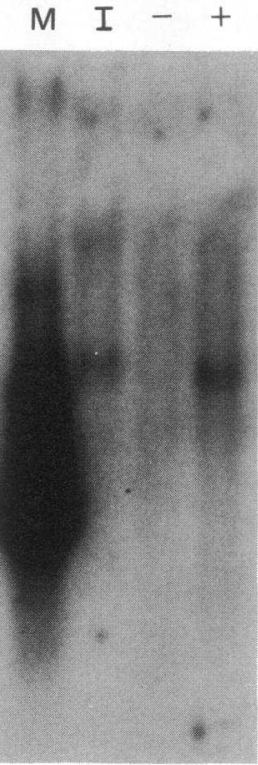

$2711-2730$

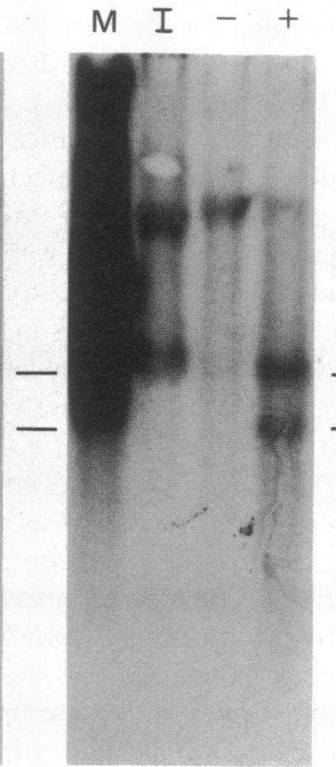

4089-4108

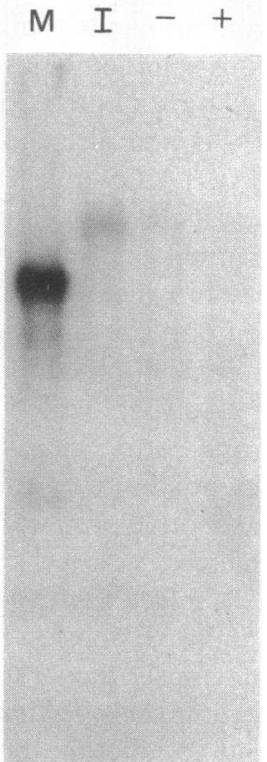

4499-4518

Figure 2. Typical Northern hybridizations using oligonucleotide probes to detect the HSV-1 LATs. The larger LAT is seen at $1.85 \mathrm{~kb}$, the smaller LAT is at $1.35 \mathrm{~kb}$. Each blot contains RNA from HSV-1-infected Vero cells (MOI 2, harvested at $20 \mathrm{~h}$, lanes marked $I$ ), RNA from a human trigeminal ganglion preparation previously shown to include (lanes marked +) or not to include (lanes marked -) both LATs by Northern hybridization, or in vitro synthesized control marker RNAs at 2,866 b (from bases 2,913 to 5,779), $1660 \mathrm{~b}$ (from bases 1,479 to 3,139 ), and $786 \mathrm{~b}$ (from bases 2,127 to 2,913 ) (all in lanes marked $M$ ).

4,108, however, detected both the $1.85-\mathrm{kb}$ and the $1.35-\mathrm{kb}$ LAT RNAs in ganglia extracts, and again only the $1.85 \mathrm{~kb}$ LAT from infected cells. The probe representing bases 4,4994,518 detected only the control RNA, and neither LAT from ganglion or infected Vero cell RNAs. Small amounts of $28 \mathrm{~S}$ ribosomal RNA (migrating at $\sim 4.4 \mathrm{~kb}$ ) were also seen in these hybridizations. Results of hybridizations using these and other oligonucleotide probes spanning the LAT region are summarized in Table I.
The obvious interpretation of the results of this series of experiments is that transcription of the HSV-1 LATs is initiated somewhere in the region of bases 2,301-2,307 and that the smaller RNA is a spliced form of the larger one with an intron excised from the region between bases 2,419-2,711 and $3,134-3,201$. We found no evidence for additional splices using these probes.

LAT initiation site. To precisely localize the $5^{\prime}$ end of these LATs, we performed a primer extension analysis on RNA

Table I. Results of Northern Hybridizations of RNA Extracted from HSV-1 KOS-infected Vero Cells and Latently Infected Human Trigeminal Ganglia Using Synthetic Oligonucleotide Probes

\begin{tabular}{|c|c|c|c|c|}
\hline \multirow[b]{3}{*}{ Position } & \multirow[b]{3}{*}{ Sequence } & \multicolumn{3}{|c|}{ Transcript detected } \\
\hline & & \multirow[b]{2}{*}{$\begin{array}{l}\text { Vero cells } \\
1.85 \mathrm{~kb}\end{array}$} & \multicolumn{2}{|c|}{ Ganglia } \\
\hline & & & $1.85 \mathrm{~kb}$ & $1.35 \mathrm{~kb}$ \\
\hline $2282-2301$ & TGGAAACGCGGCGTCTTTGT & - & - & - \\
\hline $2307-2326$ & GGGAGAAGCAGGTGTCTAAC & + & + & + \\
\hline $2400-2419$ & CTGGTGTGCTGTAACACGAG & + & + & + \\
\hline $2711-2730$ & CGTATCCTCGCTTTAGGAAC & + & + & - \\
\hline $3115-3134$ & CTATAGGGCAACAAAGGATG & + & + & - \\
\hline $3202-3221$ & GTGTGGGTGTTAAGTTTCCG & + & + & + \\
\hline $3487-3506$ & CTGTCTGTGTTGGATGTATC & + & + & + \\
\hline $4089-4108$ & GGTCTCTAGCGTGGTCGCCC & + & + & + \\
\hline $4176-4195$ & GAGGAAGTGTGCCCGGAAGA & + & + & + \\
\hline $4499-4518$ & GAAAACCCCTCCCCCCAGTC & - & - & - \\
\hline
\end{tabular}

Shown are the positions and sequences of the oligonucleotide probes used and the results of Northern hybridization with RNA extracted from HSV-1 infected Vero cells and latently infected human trigeminal ganglia. Oligonucleotide probes are numbered relative to the junction of the unique long $\left(U_{L}\right)$ and long internal repeat $\left(I_{L}\right)$ segments. 
from human trigeminal ganglia. The primer used in these reactions spanned bases $2,400-2,419$, and hybridized to both the 1.85-kb and the 1.35-kb LATs, as shown in Fig. 2. As controls, RNAs were also chosen from extracts of uninfected Vero cells, HSV-1 KOS-infected cells and from cells infected with a low passage HSV-1 clinical isolate. RNAs from three human trigeminal ganglia were studied, two of which were positive and one of which was negative for the LATs by Northern hybridization. The sizes of the extension products in each reaction were determined relative to a DNA sequence ladder.

Autoradiograms of gels containing primer extended RNA from Vero cells infected with HSV-1 strain KOS showed an intense discrete band at 117 bases from the $5^{\prime}$ end of the oligonucleotide primer; no corresponding band was seen using uninfected Vero cells (Fig. 3). Primer extension of RNA from cells infected with a clinical isolate gave rise to a band one base smaller. Extension reactions with ganglion RNA preparations previously shown to contain both LATs by Northern hybridization each yielded a single intense discrete band (ganglia 1 and 2), and the primer extension product of RNA from a negative ganglion preparation (ganglion 3) yielded no band. The extended products of the positive ganglia showed slight variation in the size of this band, compatible either with a single base difference in the $5^{\prime}$ start site or a single base deletion in the sequence of one latent HSV-1 genome relative to the other in this region. A fainter band is seen $\sim 35$ bases above this band in ganglion number 1 . As this is not seen in either the other positive ganglion or the negative ganglion, it is not clear whether it represents the $5^{\prime}$ end of a minor latency-associated RNA species initiated further upstream from the more abundant LATs. Because of a single base difference in the sequences near the $5^{\prime}$ end of LAT between strain KOS (8) and strain 17 (22), these data indicate that the $5^{\prime}$ end of the major HSV-1 LATs is 2,304 bases from the junctions of the long repeats and the $\mathrm{U}_{\mathrm{L}}$ segment in virus strain 17 .

$L A T$ kinetics. In acute infection, $\mathrm{HSV}$ gene expression occurs in a coordinated, cascade fashion over a period of 12-18 h. By 1-2 h after infection, 5 viral "immediate-early" (alpha) genes are transcribed. These regulate and promote the synthesis of over a dozen viral "early" (beta) gene products necessary for DNA replication. By 6-10 h after infection, numerous viral "late" (gamma) gene products are synthesized, which participate in virus assembly, maturation, and release.

In the following experiments our goal was to determine the temporal order of HSV-1 LAT gene expression by using drug block techniques. To do this, RNAs were extracted at various time points after HSV-1 infection from cells treated or untreated with cycloheximide or acyclovir. Cycloheximide is known to block transcription of all HSV-1 RNAs that are dependent upon earlier synthesis of viral proteins, namely the viral early and late genes. Acyclovir inhibits the transcription of HSV-1 late genes, whose expression is dependent upon ear-

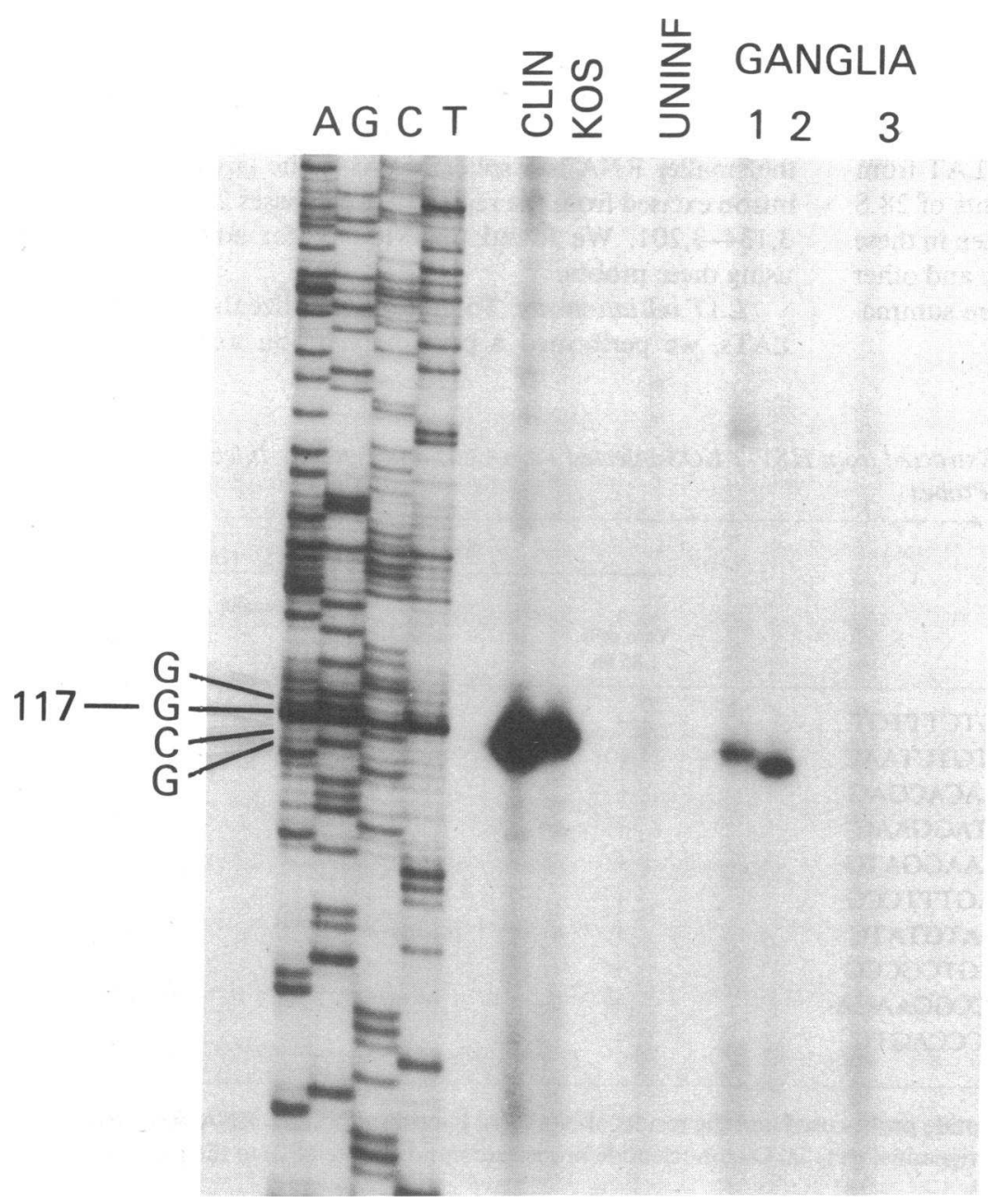

Figure 3. Primer extension to determine the $5^{\prime}$ end of the LATs. The RNA used was extracted from Vero cells acutely infected with a low passage HSV-1 clinical isolate (lane marked $C L I N$ ) or strain KOS (lane marked $K O S$ ), from uninfected Vero cells (lane marked $U N I N F$ ), and from human trigeminal ganglia shown to contain both species of LAT by Northern hybridization (lanes marked 1 and 2 ), and from a human trigeminal ganglion shown not to contain detectable levels of either LAT by Northern hybridization (lane marked 3). An unrelated human DNA sequence is shown as a size marker. The $5^{\prime}$ end of the LATs was detected 117 bases upstream of the end of the primer (which spanned bases 2,400-2,419). 
lier viral DNA synthesis. The 1,256-bp Sal I-Hinc II subfragment was gel purified and used as a DNA probe in Northern hybridization analyses of the RNAs. This probe detects the 2.6-kb immediate-early ICPO transcript and both the $1.85-\mathrm{kb}$ and 1.35-kb LATs (15)

In the first drug block experiment Vero cells were treated with cycloheximide $(50 \mu \mathrm{g} / \mathrm{ml})$ starting at $3 \mathrm{~h}$ before infection with $5 \mathrm{pfu} /$ cell of a low passage HSV-1 clinical isolate. Total RNA was extracted $18 \mathrm{~h}$ after infection and analyzed by Northern hybridization (Fig. 4). Cycloheximide treatment substantially reduced LAT levels as compared to that seen in RNA from untreated infected cells. RNA species migrating at $\sim 4.2 \mathrm{~kb}$ proved upon subsequent hybridization with a singlestranded oligonucleotide probe to be homologous to the ICPO

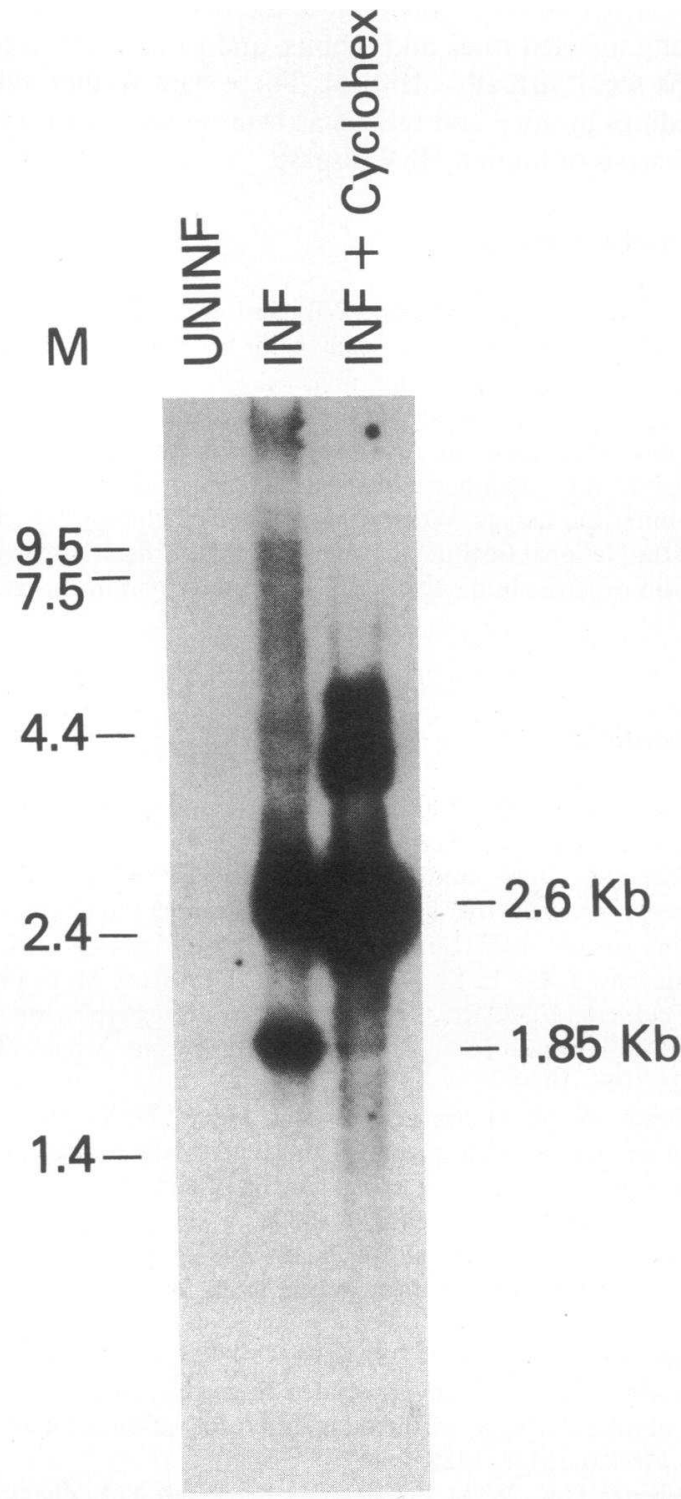

Figure 4. LAT expression in the presence of cycloheximide. RNA extracted from uninfected Vero cells (lane UNINF) or Vero cells infected with an HSV-1 clinical isolate in the presence (lane $I N F+C y$ clohex) or absence (lane $I N F$ ) of cycloheximide was hybridized with a gel pure 1,256-bp Sal I-Hinc II DNA probe. gene and to be transcribed from the same strand as the ICPO message (data not shown), thus suggesting it to be an ICP0 splicing precursor. In cycloheximide-treated cells, transcription of both the $2.6-\mathrm{kb}$ ICP0 message and of the 4.2-kb ICP0related message were increased.

In the second series of studies the time course of, and the effect of acyclovir on LAT gene expression was investigated (Fig. 5). Hybridizations of RNA extracted from cells infected with a low multiplicity $(0.1 \mathrm{pfu} /$ cell $)$ of $\mathrm{HSV}-1$ strain KOS (lanes marked $L O$ ) showed no LAT expression at $6 \mathrm{~h}$, although the 2.6-kb ICPO RNA was already evident. By $24 \mathrm{~h}$ after infection, the $1.85-\mathrm{kb}$ LAT was detectable. Using RNA from cells infected with a higher virus multiplicity ( $2 \mathrm{pfu} /$ cell, $H I$ lanes in Fig. 5), ICP0 RNA could be seen as early as $2 \mathrm{~h}$ after infection, while no LAT was detected either $2 \mathrm{~h}$ or $6 \mathrm{~h}$ after infection. By $24 \mathrm{~h}$, the $1.85-\mathrm{kb}$ LAT was readily seen. In cells infected with 2 pfu/cell and treated with $30 \mu \mathrm{M}$ acyclovir to inhibit viral DNA synthesis, ICP0 RNA was seen at $6 \mathrm{~h}$, but was no longer apparent at $24 \mathrm{~h}$. LAT RNAs were never evident in extracts from the acyclovir-treated HSV-1 infected cells.

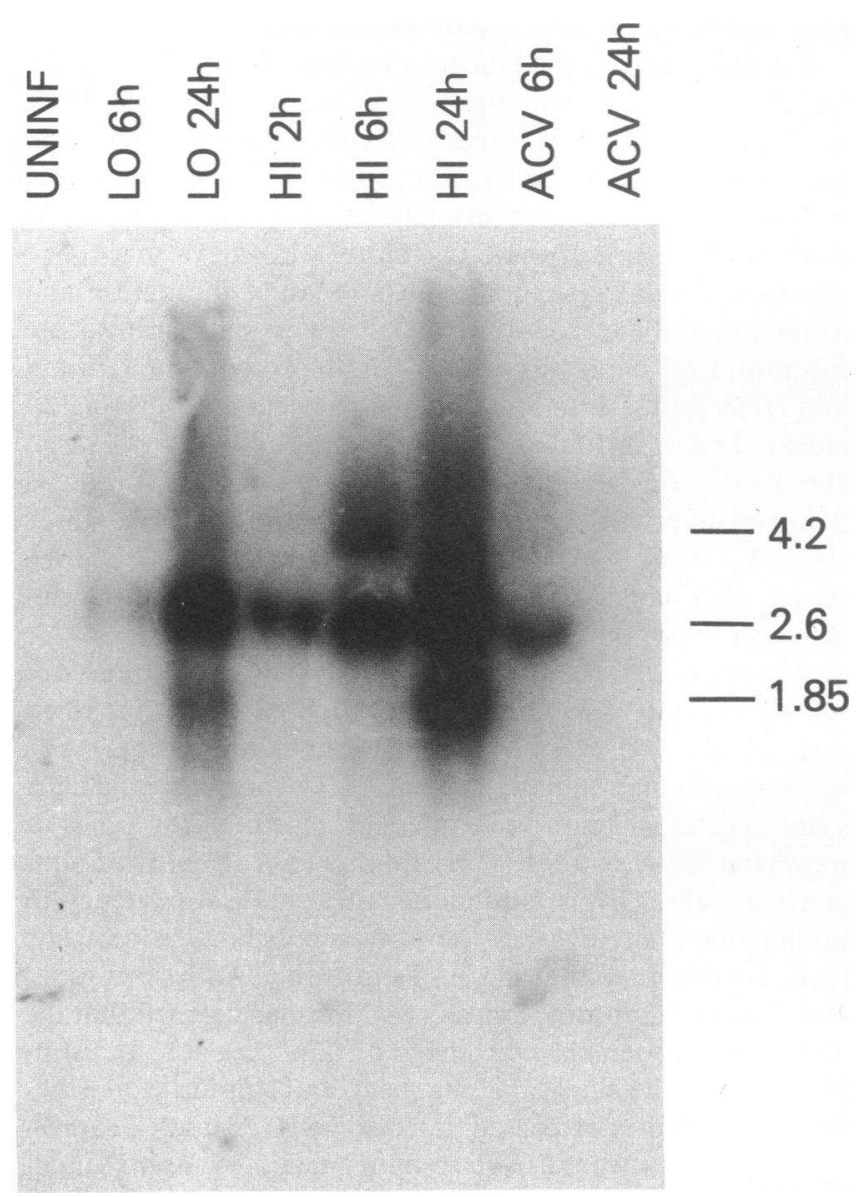

Figure 5. Kinetic analysis of LAT expression and effect of acyclovir on LAT expression. RNA from uninfected Vero cells (lane UNINF) or from Vero cells infected at a low multiplicity $(0.1 \mathrm{pfu} / \mathrm{cell}) \mathrm{ex}$ tracted at 6 (lane $L O 6 h$ ) or 24 (lane $L O 24 h$ ) h after infection; Vero cells infected at a higher multiplicity ( 2 pfu/cell) extracted at 2 (lane $H I 2 h$ ), 6 (lane $H I 6 h$ ), or 24 (lane $H I 24 h$ ) h after infection; or acyclovir-treated Vero cells infected at a multiplicity of 2 pfu/cell extracted at 6 (lane $A C V 6 h$ ) or 24 (lane $A C V 24 h$ ) h was hybridized with a gel pure 1,256-bp Sal I-Hinc II DNA probe. 
The data in Figs. 4 and 5 reveal that HSV-1 1.85-kb LAT is not expressed early in infection, and that its synthesis, or at least its accumulation to detectable levels, requires both protein and viral DNA synthesis. Thus, HSV-1 LAT is expressed in a manner similar to that of the many HSV-1 "late" (gamma) genes.

\section{Discussion}

In this report we summarize our findings with respect to the structure, localization, splicing and kinetics of the HSV-1 LATs in human ganglia and in cell culture. By Northern hybridization with oligonucleotide probes, two LATs, $1.85 \mathrm{~kb}$ and $1.35 \mathrm{~kb}$ in length, are recognized (Table I, Fig. 2). Primer extension analysis fixed the $5^{\prime}$ ends of these LATs from the diploid latency gene at 2,304 bases from the junctions of the repeat and unique long segments (or at genome bases 6,911 and 119,461 relative to the strain 17 sequence; Fig. 3), i.e., within two bases of the location assigned in rabbit and murine studies $(8,9)$. Both LATs possess identical $5^{\prime}$ ends but the smaller transcript differs from the larger one by excision of a single intron that is $400-800$ bases in length.

Comparison of our data on the structure of the $1.85-\mathrm{kb}$ LAT in human trigeminal ganglia shows no differences from that found in acutely infected Vero cells. Northern hybridizations of each yielded equivalent results with oligonucleotide probes, and primer extension analysis showed that these RNAs also have the same $5^{\prime}$ end. Therefore, we believe that tissue culture is a valid system in which to study the nature and expression of these genes during acute infection. During acute infection, LAT expression requires both protein synthesis and viral DNA synthesis to accumulate to detectable levels (Figs. 4 and 5). This is in full concordance with Spivack and Fraser, who also found LAT to require protein and DNA synthesis (25), but differs from the report of Wagner et al. (7), which concluded that LAT is transcribed as an immediate-early gene. During HSV latency, there is no evidence for viral transcription (other than that leading to the production of LAT) or for viral DNA synthesis. This suggests either that LAT transcription occurs only during the acute ganglionic infection when viral protein and DNA synthesis occur and that the LATs persist due to high stability, or that LAT expression in ganglia is not dependent upon the expression of other viral genes or upon viral DNA synthesis, as it appears to be in cultured nonneuronal cells. Given the maintenance of HSV-1 latency in humans for many decades the former possibility is unlikely. Thus, we conclude that the LATs must be synthesized in latently infected neurons. Spivack and Fraser suggested that the HSV-1 latency gene be considered a "lambda gene" to distinguish it from the classical alpha, beta, and gamma viral genes defined by studies of acutely infected cells (25). LAT expression in neurons would have to be regulated by, as-yet undefined, host, or viral factors which evolve in the context of the unique milieu of these terminally differentiated, nondividing cells.

The HSV-1 LATs have been shown to play a role in promoting reactivation by cocultivation in tissue culture of ganglia from latently infected mice. Viruses with mutations upstream of the LAT gene produce no LAT but are capable of establishing latency (11-13). A viral mutant lacking sequences in the long repeats and producing no LAT was able to reacti- vate upon explant cocultivation of latently infected ganglia from latent infection, but at a lower rate than virus without these mutations. Nine of ten ganglia from mice infected with nonmutated virus had reactivated by $7 \mathrm{~d}$, while the first reactivation of mutant virus occurred after $10 \mathrm{~d}$, and by $31 \mathrm{~d}$ virus had reactivated from only 14 of 18 ganglia. This mutant virus was also less lethal to mice ( 21 vs. $62 \%$ death rate) (13). In separate studies, virus containing a different deletion mutation preventing LAT expression was also able to establish latency. Only 21 of 43 cocultivated ganglia yielded this virus, while virus recovery rates from ganglia infected with the wild-type and marker rescued virus were 17 of 18 and 17 of 20 , respectively. This mutant virus exhibited normal growth characteristics in culture, and exhibited no alteration in virulence (12). Although these data failed to elucidate the mechanism of LAT action, they did establish a role for the LATs in modulating viral reactivation and possibly virulence.

The structure and expression of the HSV-1 LATs in experimentally infected mice and rabbits, and in naturally infected humans seem virtually identical. These data further validate the findings in mice and rabbits as bearing on the nature and pathogenesis of human HSV disease.

\section{Acknowledgments}

Sunil Nagpal, Alison Freifeld, and William Reinhold provided helpful suggestions. We thank Barbara Spalholz for her primer extension protocol, Duncan McGeoch for unpublished HSV-1 sequence information, Harry Malech for critical review of this paper, and Pat Stallsmith for manuscript preparation. Also, special thanks to John Smialek and Mario Golle of the Baltimore Medical Examiners office for assistance in obtaining the tissues. We are particularly indebted to Dr. David Katz of the National Institute of Neurological Disorders and Stroke for sharing his expertise in the removal and handling of human trigeminal ganglia.

\section{References}

1. Corey, L., and P. G. Spear. 1986. Infections with herpes simplex viruses. $N$. Engl. J. Med. 314:686-691.

2. Mellerick, D. M., and N. W. Fraser. 1987. Physical state of the latent herpes simplex virus genome in a mouse model system: evidence suggesting an episomal state. Virology. 15:265-275.

3. Stevens, J. G., E. K. Wagner, G. B. Devi-Rao, M. Cook, and L. T. Feldman. 1987. RNA complementary to a herpesvirus alpha gene mRNA is prominent in latently infected neurons. Science (Wash. DC). 235:1056-1059.

4. Deatly, A. M., G. Spivack, E. Lavi, and W. Fraser. 1987. RNA from an immediate early region of the type 1 herpes simplex virus genome is present in the trigeminal ganglia of latently infected mice. Proc. Natl. Acad. Sci. USA. 84:3204-3208.

5. Spivack, J. G., and N. W. Fraser. 1987. Detection of herpes simplex virus type 1 transcripts during latent infection in mice. $J$. Virol. 61:3841-3847.

6. Spivack, J. G., and N. W. Fraser. 1988. Expression of herpes simplex virus type 1 latency-associated transcripts in the trigeminal ganglia of mice during acute infection and reactivation of latent infection. J. Virol. 62:1479-1485.

7. Wagner, E. K., W. M. Flanagan, G. Devi-Rao, Y. F. Zhang, J. M. Hill, K. P. Anderson, and J. G. Stevens. 1988. The herpes simplex virus latency-associated transcript is spliced during the latent phase of infection. J. Virol. 62:4577-4585.

8. Wagner, E. K., G. Devi-Rao, L. T. Feldman, A. T. Dobson, Y. Zhang, W. M. Flanagan, and J. G. Stevens. 1988. Physical character- 
ization of the herpes simplex virus latency-associated transcript in neurons. J. Virol. 62:1194-1202.

9. Wechsler, S. L., A. B. Nesburn, R. Watson, S. M. Slanina, and H. Ghiasi. 1988. Fine mapping of the latency-related gene of herpes simplex virus type 1: alternate splicing produces distinct latency-related RNAs containing open reading frames. J. Virol. 62:4051-4058.

10. Perry, L. F., F. J. Rixon, R. D. Everett, M. G. Frame, and D. J. McGeoch. 1987. Characterization of the IE1 10 gene of herpes simplex virus type 1. J. Gen. Virol. 67:2365-2380.

11. Javier, R. T., J. G. Stevens, V. B. Dissette, and E. K. Wagner 1988. The herpes simplex virus transcript abundant in latently infected neurons is dispensable for establishment of the latent state. Virology. 166:254-257.

12. Leib, D. A., C. L. Bogard, M. Kosz-Vnenchak, K. A. Hicks, D. M. Coen, D. M. Knipe, and P. A. Schaffer. 1989. A deletion mutant of the latency-associated transcript of herpes simplex virus type 1 reactivates from the latent state with reduced frequency. J. Virol. 63:2893-2900.

13. Steiner, I., J. G. Spivack, R. P. Lirette, S. M. Brown, A. R. Maclean, J. Subak-Sharpe, and N. W. Fraser. 1989. Herpes simplex virus latency-associated transcripts are evidently not essential for latent infection. EMBO (Eur. Mol. Biol. Organ.) J. 8:505-511.

14. Croen, K. D., J. M. Ostrove, L. J. Dragovic, J. E. Smialek, and S. E. Straus. 1987. Latent herpes simplex virus in human trigeminal ganglia. N. Engl. J. Med. 314:1427-1432.

15. Krause, P. R., K. D. Croen, S. E. Straus, and J. M. Ostrove. 1988. Detection and preliminary characterization of herpes simplex virus type 1 transcripts in latently infected human trigeminal ganglia. J. Virol. 62:4819-4823.

16. Stevens, J. G., L. Haarr, D. D. Porter, M. L. Cook, and E. K. Wagner. 1988. Prominence of the herpes simplex virus latency-associated transcript in trigeminal ganglia from seropositive humans. $J$. Infect. Dis. 158:117-123.
17. Steiner, I., J. G. Spivack, D. R. O'Boyle, E. Lavi, and N. W. Fraser. 1988. Latent herpes simplex virus type 1 transcription in human trigeminal ganglia. J. Virol. 62:3493-3496.

18. Gordon, Y. J., B. Johnson, E. Romanowski, and T. AraulloCruz. 1988. RNA complementary to herpes simplex type 1 ICP0 gene demonstrated in neurons of human trigeminal ganglia. J. Virol. 62:1832-1835.

19. Wechsler, S. L., A. B. Nesburn, R. Watson, S. Slanina, and H. Ghiasi. 1988. Fine mapping of the major latency-related RNA of herpes simplex virus type 1 in humans. J. Gen. Virol. 69:3101-3106.

20. Chirgwin, J. M., A. E. Przbyla, R. J. MacDonald, and W. J. Rutter. 1979. Isolation of biologically active ribonucleic acid from sources enriched in ribonuclease. Biochemistry. 18:5294-5299.

21. Melton, D. A., P. A. Kreig, M. R. Rebagliati, T. Maniatis, K. Zinn, and M. R. Green. 1984. Efficient in vitro synthesis of biologically active RNA and RNA hybridization probes from plasmids containing a bacteriophage SP6 promoter. Nucleic Acids Res. 12:70357056.

22. Ostrove, J. M., W. Reinhold, C. Fan, S. Zorn, J. Hay, and S. E. Straus. 1985. Transcription mapping of the varicella-zoster virus genome. J. Virol. 56:600-606.

23. McGeoch, D. J., M. A. Dalrymple, A. J. Davison, A. Dolan, M. C. Frame, D. McNab, L. J. Perry, J. E. Scott, and P. Taylor. 1988 The complete DNA sequence of the long unique region in the genome of herpes simplex virus type 1. J. Gen. Virol. 69:1531-1574.

24. Spalholz, B. A., P. F. Lambert, C. L. Yee, and P. M. Howley. 1987. Bovine papilloma virus transcriptional coagulation: localization of the E2-responsive elements of the long control region. J. Virol. 61:2128-2137.

25. Spivack, J. G., and N. W. Fraser. 1988. Expression of herpes simplex virus type 1 (HSV-1) latency-associated transcripts and transcripts affected by the deletion in a virulent mutant HFEM: evidence for a new class of HSV-1 genes. J. Virol. 62:3281-3287. 